\title{
A Review of Reliability Analysis for Water Quality in Water Distribution Systems
}

\author{
Jinhui Huang, Edward A. McBean, and William James
}

A review of reliability research for water distribution systems demonstrates that, to date, little is currently available characterizing water quality reliability indices. The incidence of micro-organism-caused outbreaks of waterborne disease demonstrates a number of causes, most of which are the result of water treatment system deficiencies. However, the basis for a change in this situation is projected as a result of the increasing age of distribution system components, increasing urban populations, per capita water demands, and deterioration of water distribution infrastructure. Although there is no universal agreement on how to define, or measure, the reliability of a water distribution system, this Chapter reviews the alternatives for characterizing reliability, demonstrating some of the strengths and weaknesses, and provides areas of future research.

\subsection{Introduction}

In a broad sense, 'reliability' is a measure of the performance of a system. Although alternatives exist, a reasonable definition of the reliability of a system is the probability that the system operates successfully over a specified time. As systems become more complex, issues of reliability increase in importance, including the need/ability to identify areas needing improvement.

As drinking water is essential to human life, society requires water distribution systems to function properly under both normal and abnormal

Huang, J., E. McBean and W. James. 2005. "A Review of Reliability Analysis for Water Quality in Water Distribution Systems." Journal of Water Management Modeling R223-07. doi: 10.14796/JWMM.R223-07. (C) CHI 2005 www.chijournal.org ISSN: 2292-6062 (Formerly in Effective Modeling of Urban Water Systems. ISBN: 0-9736716-0-2) 
conditions. This means that for a reliable water supply system, water must be (i) available on demand, (ii) delivered at a sufficient pressure for proper use, and (iii) safe in terms of quality. Although reliability of a water supply system in general is a measure of performance in terms of the three factors indicated, undesirable events/failure will occur which will cause a decline or interruption in system performance. The reliability of a water supply system can be considered under three types of failure: mechanical, hydraulic and water quality failure.

Mechanical failures, also termed component failures, may, for example, be pipe breakage, pump failure, power outages, or control valve failure. Changes in demand or in pressure head may result in hydraulic failures. These failures may be due to, for example, old pipes with varying roughness, inadequacy in pipe size due to increased water demands, insufficient pumping capacity, and insufficient in-system storage capacity. Water quality failure may be defined as occurrences where the concentrations of contaminants exceed the maximum contaminant level (MCL) defined by water quality standards. The major concern for water quality failure is the adverse effect on the health of humans.

Due to the importance of water supply systems for the needs of society and for industrial growth, reliability studies have become of increasing importance for water distribution systems where considerations of planning, design and operations are integrated. However, quantifying the reliability of a water supply system continues to be a major problem.

For confident decision-making, a set of meaningful and appropriate reliability measures need to be defined, wherein all the measures must be computationally feasible. Reviews of the literature by Mays (1996) and Engelhardt et al. (2000) revealed that that there is no universal agreement on how to define, or measure, the reliability of a water distribution system. This Chapter reviews the alternatives for characterizing reliability, demonstrating some of the strengths and weaknesses, and provides areas of future research.

\subsection{Reliability Index}

Although no single measure of reliability is universally accepted, alternatives have been suggested depending on the purpose of the reliability study. Published alternative measures include:

1. Index of Potential to Meet Critical Events. If a system can satisfy demand under a defined set of contingencies, for example, the 
drought of record, or a key component failure, or other emergency loading, the system may be judged to be reliable. This is a very common approach adopted by design practices and this approach usually does not use a quantitative index (e.g. Mays, 2000);

2. Availability Indices. Availability can be defined as the probability $\mathrm{A}(\mathrm{t})$ that the system is functioning well at time $t$; e.g. the demand does not exceed available supply or capacity, pressure is in the acceptable range (e.g. Goulter and Coals 1986; Su et al., 1987; Cullinane et al., 1992; Mays et al., 2002; Fujiwara and Tung, 1991; Fujiwara and Li, 1998; Tanyimboh et al., 1999).

3. Frequency and Duration Indices. These types of indices indicate frequency and duration failures (e.g. Osfeld et al., 2002);

4. Water Quality Indices: water quality indices have been defined to be the probability that the concentration $C$ of one contaminant does not exceed the $M C L$, where the concentration $C$ is a function of time $t$, and space $x$ (e.g. Mays 1996, 2002; Gauthier et al., 2000).

5. Risk Indices. Risk indices have been defined as either the probability of failure only or the product of the failure severity and occurrence probability (e.g. Sadiq et al., 2004; Babovic et al., 2002).

6. Resilience Indices: Resilience Indices have been defined as the intrinsic capacity of a water distribution system to overcome sudden failures. It can be considered a measure of the combined effect of surplus power and nodal uniformity (e.g. Todini, 2000; Prasad and Park , 2004).

7. Economic Indices on Failure Consequence. These indices indicate the economic consequences of shortages. Some research also refers to them as vulnerability (Mays, 2000).

It is recognized that indices focusing on water quality are limited. As is apparent in the above listing, most research has focused on either the mechanical reliability or the hydraulic reliability of water distribution systems. Research on water quality reliability in water distribution systems has generally been addressed in relatively simplistic terms, such as the failure to maintain a certain level of disinfectant residual, and the total time of failure for which the contaminant concentration is above a threshold, both of which are characterizations on the basis of past monitoring. The characterization of water quality problems by these measures is insufficient, since they are neither comparable nor extendable. For example, if concern is with more than 
one contaminant, there is no mechanism to integrate the concern into an overall index.

The authors reviewed a number of reliability studies listed in the references at the end of this Chapter and, from the review, it can be concluded that research on reliability of water quality is less than the research on mechanical and hydraulic reliability. The availability index is a traditional measurement and is still a dominant way to quantify hydraulic reliability. The resilience index proposed by Todini (2000) for hydraulic reliability has been used in design optimization (Prasad and Park, 2004). For water quality reliability analyses, the scaled risk index proposed by Sadiq et al. (2004) has been found to be the most comprehensive measure to date. It integrates the environmental risk assessment pathway approach into the traditional reliability research by identifying each risk pathway, weighing risk severity and scaling the risk occurrence probability. However, the use of this index depends on establishing a sound and consistent risk scaling and weighting system.

\subsection{Reliability models for water distribution systems}

From our literature review, there are evidently numerous ways that a water distribution system may be unreliable. In general, all failures may be categorized into two major modes:

- component (mechanical) failure; and

- performance failure.

As explained in section 7.2, component failure involves the failure of individual network components, e.g. pipes, pumps and valves, while performance failure arises when the design objectives are not satisfied at one or more nodes within the water distribution system in terms of the pressure, flow and quality. Component failure may be largely responsible for performance failure, and decreases the reliability of the performance of a water distribution system. For example, water quality failure may arise as a result of a component failure in the treatment plant, or contamination occurring within the transmission network caused by pipe breakage or leakage. On the other hand, water quality failure may also decrease the component reliability. For example, contaminant intrusion may exacerbate the corrosion of a pipe, form biofilms on the pipe wall, and consequently change the roughness property, and hence reduce the pipe conveyance capacity. 


\subsubsection{Concepts of Mechanical (Component) Reliability}

Mechanical reliability is a basic concept in the system reliability field. It is usually defined as the probability that a component or subcomponent performs its mission for a given period of time $(0, t)$ under a specified condition. In other words, the reliability $R(t)$ of a component may be expressed as the probability that the time to failure $T>t$, assuming the component is new or repaired at $t=0$. The reliability can be expressed as follows:

$$
R(t)=P\{T>t\}=\int_{t}^{\infty} f(t) d t
$$

where $f(t)$ is the probability density function (pdf) of the time to failure.

The pdf $f(t)$ may be developed from component failure data, using various statistical methods. The unreliability $F(t)$ of a component is defined as the probability that the component will fail by time $t . F(t)$ can thus be expressed:

$$
F(t)=P\{T<t\}=1-R(t)=1-\int_{0}^{t} f(t) d t
$$

Denoting $m(t)$ the failure rate, the probability that a component experiences a failure per unit of time $t$ given that the component was operating at time zero and has survived to time $t, m(t)$ can be also stated to be the probability that a component of age $t$ will fail in the next moment. Therefore, $m(t)$ can be expressed:

$$
m(t)=P\{T \in(t, t+d t) \mid T>t\}=\frac{d R(t) / d t}{R(t)}=\frac{f(t)}{R(t)}=\frac{f(t)}{1-F(t)}
$$

From Equation 7.3, Equation 7.4 can be derived:

$$
\int_{0}^{t} m(t) d t=\int_{0}^{t} \frac{f(t)}{1-F(t)} d t=\int_{0}^{t} \frac{-d F(t) / d t}{1-F(t)} d t=-\ln [1-F(t)]
$$

which implies:

$$
1-F(t)=\exp ^{\left\{-\int_{0}^{t} m(t) d t\right\}}
$$


The mean time to failure (MTTF) is the expected value of the time to failure, stated mathematically as:

$$
\text { MTTF }=\int_{0}^{\infty} t f(t) d t
$$

which is expressed in years, days, or hours. The MTTF is the inverse of the failure rate $\mathrm{m}(\mathrm{t})$.

In similar fashion, the repair density function describes the random characteristics of the time required to repair a failed component when failure occurs at time zero. The probability of repair, $G(t)$, is the probability that the component repair is completed before time $t$, given that the component failed at time zero. Note that the repair process starts with a failure at time zero and ends at the completion of the repair at time $t$. Thus, the mean time to repair (MTTR) is the expected value of the time to repair a failed component, as expressed in Equation 7.7:

$$
\text { MTTR }=\int_{0}^{t} \operatorname{tg}(t) d t
$$

Therefore, for a repairable component, the mean time between failures (MTBF) is defined

$$
\mathrm{MTBF}=\mathrm{MTTF}+\mathrm{MTTR}
$$

A model may be constructed representing the time-to-failure of the entire system based on the lives of the components of which it is composed.

A water distribution system normally can be considered in two typical configurations: in series and in parallel. In a series configuration, a failure of any component results in failure for the entire system. The reliability of the system is the probability that unit 1 succeeds, and unit 2 succeeds, and all of the other units in the system succeed. So, all $n$ units must succeed for the system to succeed. If the reliability of each component is independent of all other components, the reliability of the system is given by:

$$
R_{s}=\prod_{i=1}^{n} R_{i}
$$

where:

$$
\begin{aligned}
& R_{s}=\text { reliability of the overall system, and } \\
& R_{i}=\text { reliability of the unit } i, \text { which is functioning. }
\end{aligned}
$$

In a simple parallel system, as shown in Figure 7.1, at least one of the units must succeed for the system to succeed. Units in parallel are also referred to 
as redundant units. Redundancy is a very important aspect of system design and reliability, adding redundancy is one of several methods of improving water supply system reliability, for both quantity and quality concerns.

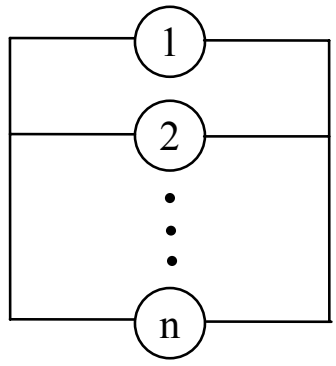

Figure 7.1 Simple Parallel System

The probability of failure, or unreliability, for a system with $n$ statistically independent parallel components is the probability that unit 1 fails and unit 2 fails, and all of the other units in the system fail. In a parallel system, all $n$ units must fail for the system to fail. In other words, if unit 1 succeeds or unit 2 succeeds or any of the $n$ units succeeds, then the system succeeds. The unreliability of the system may then be written:

$$
F_{S}=P\left(X_{1} \bigcap X_{2} \bigcap \ldots \bigcap X_{n}\right)=P\left(X_{1}\right) P\left(X_{2} \mid X_{1}\right) \ldots P\left(X_{n} \mid X_{1} X_{2} \ldots X_{n-1}\right)
$$

Where:

$$
\begin{aligned}
F_{S} & =\text { unreliability of the system, } \\
X_{i} & =\text { event of failure of unit } \mathrm{i} \text {, and } \\
P\left(X_{i}\right) & =\text { probability of failure of unit } i .
\end{aligned}
$$

In the case where the failure of a component affects the failure rates of other components, then the conditional probabilities in equation (3.10) must be considered. However, in the case of independent components, equation (3.10) becomes:

$$
F_{S}=P\left(X_{1}\right) P\left(X_{2}\right) \ldots P\left(X_{n}\right)
$$

Or in terms of component unreliability:

$$
F_{S}=\prod_{i=1}^{n} F_{i}
$$


Observe the contrast with the series system in which the system reliability was the product of the component reliabilities, whereas the parallel system has the overall system unreliability as the product of the component unreliabilities.

The reliability of the parallel system is then given by:

$$
\mathrm{R}_{\mathrm{S}}=1-\mathrm{F}_{\mathrm{S}}=1-\left(\mathrm{F}_{1} \mathrm{~F}_{2} \ldots \mathrm{F}_{\mathrm{n}}\right)=1-\left[\left(1-\mathrm{R}_{1}\right)\left(1-\mathrm{R}_{2}\right) \ldots\left(1-\mathrm{R}_{\mathrm{n}}\right)\right]=1-\prod_{i=1}^{n}\left(1-R_{i}\right)
$$

For a larger system, which involves both series and parallel configurations, the reliability of the entire system can be analyzed by calculating the reliabilities for the individual series and parallel sections and then combining them in an appropriate manner.

An application of the above parallel/series reliability to a water system in Japan under earthquake condition was reported by Hosoi and Kido, in 2001. Hosoi and Kido divided the water distribution system into six subsystems. Each subsystem was supplied by a primary reservoir and was further divided into some series-parallel or parallel-series systems by pumping stations and transmission reservoirs. The failure rate of each component in the system was developed from data observed from a previous earthquake event, and then a model was used to estimate the overall reliability for the entire system.

\subsubsection{Pipe Deterioration and Pipe Failure Probability}

Failures of network components including pipes and pumps are major causes of a network failure. According to Kleiner and Rajani (2001), pipe systems usually account for up to $80 \%$ of the total expenditure of a water supply system. The deterioration of a pipe results in not only high maintenance costs, but also loss of water, and loss of service, as well as reduction of water quality. Among all types of components of a distribution system, pipe failure is the most frequent failure occurrence since most pipes are buried and may be damaged by many factors including heavy traffic, frozen conditions, and earthquakes. A comprehensive review of physical/mechanical models on pipe failure, provided by Rajani and Kleiner (2001), revealed that a pipe's failure rate is dependent on many variables, including the pipe material, size, construction practices, soil type, age as well as ambient temperature. In particular, pipe material has a large effect on the breakage rate. Additionally, valves and pipe bridges have large effects on the pipeline failure (Hosoi and Kido, 2001). 
Kleiner and Rajani (2001) provide a critical review of the statistical models that have been proposed in the scientific literature to explain, quantify and predict pipe breakage or structural pipe failures. The statistical models are categorized into deterministic, probabilistic multi-variate, and probabilistic single-variate models that are applied to grouped data.

Ben-Akiva and Gopinath (1995) proposed an infrastructure-performance deterioration model to predict the performance of infrastructure facilities as a function of explanatory variables such as inherent infrastructure characteristics (material properties, construction quality), and extraneous characteristics: surrounding environment (e.g. ambient climate, soil types), usage of the facilities etc. Micevski et al. (2002) analyzed 497 pipes around Newcastle in Australia. Their research partly supports the Ben-Akiva and Gopinath methodology wherein they concluded that pipe properties such as diameter and material as well as soil type affect deterioration. The deterioration of smaller pipes was greater than that of larger pipes. Pipes in alluvial soils deteriorate more rapidly than those in podzolic soils.

Shamir and Howard (1979), proposed a model to consider the probability of pipe bursts following an exponential distribution, with the form of:

$$
\lambda(t)=\lambda\left(t_{0}\right) e^{A\left(t-t_{0}\right)}
$$

where:

$$
\begin{aligned}
\lambda(t) & =\text { the number of bursts } / \mathrm{y} / 1000 \mathrm{ft} \text { at time } t \\
t_{0} & =\text { base year of the analysis, } \\
\lambda\left(t_{0}\right) & =\text { number of bursts } / \mathrm{y} / 1000 \mathrm{ft} \text { at time } t_{0} \text { and } \\
A & =\text { growth rate coefficient }(1 / \mathrm{y}), \text { with } A \text { in the range of }
\end{aligned}
$$

$0.05-0.151 / y$ depending on the pipe material and diameter.

Based on Shamir and Howard results, a number of researchers have used multiple regression models to model and predict the pipe bursts (e.g. Clark et al. 1982; Walski, 1982 ; Goulter et al. 1986; and, Su et al. 1987).

Goulter and Kazemi (1988) observed significant temporal and spatial clustering of water main failures through investigating ten years of pipe breakage data in Winnipeg. Evidence was found that a repair event is very likely to trigger a subsequent breakage in close proximity soon thereafter. A non-homogeneous Poisson probability distribution was proposed to predict the probability of subsequent breaks in a pipe, given that the first break had already occurred: 


$$
P(x)=\frac{m^{x} e^{-m}}{x !} \text {, where } m=\int_{0}^{s} \int_{0}^{T} r(s, t) d t d s,
$$

where:

$$
\begin{aligned}
m= & \text { mean number of subsequent failures occurring in the } \\
& \text { cluster domain, } \\
x & =\text { number of subsequent failures occurring in the } \\
& \text { cluster domain, and } \\
r(s, t)= & \text { failure rate as a function of time } t \text { and distance } s .
\end{aligned}
$$

Babovic et al. (2002) proposed a data mining approach to derive rule sets for pipe burst analysis. This method combined machine-induced knowledge with human expert knowledge to obtain the combination and alteration of rules from different sources, e.g., human experts, decision tree analysis, and rule induction. This research helped discover the main reasons for failures and helped develop an expert system to increase the predictive accuracy of the pipe burst model.

\subsubsection{Concepts of Hydraulic Availability}

Mays (1996) defines the availability $A(t)$ of a component as the probability that the component is in operating condition at time $t$, given that the component was as good as new at $t=0$. The unavailability, $U(t)$, at time $t$ is the probability that a component is in the failed state at time $t$, given that it started in the operational state at time zero. This measurement considers pipes as repairable components. Availability is evaluated in terms of developing a required minimum pressure.

Previous work (Goulter and Coals, 1986; Su et al. 1987) proposed the use of a discrete relationship between availability and pressure: $H A_{j}=1$ for $P_{j} \geq P R$, whereas $H A_{j}=0$ for $P_{j} \leq P R$, where $H A_{j}=$ hydraulic availability of node $j ; P_{j}=$ pressure at node $j$; and $P R=$ required minimum pressure. Another approach proposed by Cullinane et al. (1992) describes an availability index as a continuous "fuzzy" function.

\subsubsection{Models and Techniques to Assess Reliability}

In the past three decades, a number of models and techniques developed for assessing the water distribution system reliability have been developed. Mays (2000) categorized them into: (i) Simulation Approaches and (ii) Analytical 
Approaches. Simulation approaches evaluate the reliability under a range of scenarios, whereas analytical approaches derive the reliability from the parameters which define the loads (or demand) on the network and from the ability of the network to meet those demands.

\section{Simulation Approaches}

Monte-Carlo simulation is often employed in the simulation approach usually involving large computational effort. Table 7.1 lists 20 different measures of reliability for simulation analysis summarized by Wagner et al. (1988b). The important advantage of simulation approaches over analytical techniques is that simulation approaches permit the use of any reliability measure that can be derived from the hydraulic performance.

\section{Analytical Approaches}

Analytical approaches assess the reliability performance based on the network's fundamental parameters (e.g. number of links connected to each node, size of pipes, location of nodes, and demands). Three major and commonly used techniques are:

1. Reachability: the connection of a specific demand node to a source node (e.g. Wagner et al., 1988a, Hosoi and Kido, 2001)

2. Connectivity: the connection of every demand node to at least one source (e.g. Wagner et al., 1988a; Fujiwara and Tung, 1991; Hobbs and Beim, 1988)

3. Cut-set: a set of links that, when removed from a network, completely disconnects one or more nodes from the remainder of the network (e.g. Su et al. 1987; Shinstine, et al. 2002).

Goulter(1988) and Jacobs and Goulter (1988) first formally proposed to use graph theory in assessing water distribution system reliability. Since then, graph theory has been applied extensively in analytical approaches (Mays, 2000). It should be noted that connection of a node is only a necessary, but not sufficient condition, for the node to meet its demands. If a pipe is too small or the pressure is too low, the flow and pressure may not be satisfied at this node. It is thus very important to integrate the graph theory associated with a system's layout aspects with the system's hydraulic aspects in order to evaluate the reliability of a water distribution system properly.

A new concept in analytical modeling was proposed by Todini (2000). Todini demonstrated the use of a resilience index to measure the reliability of a water distribution system and the performance of redundancy. This 
approach is based on a set of physical and hydraulic considerations and does not require the statistical inference on the probability distributions of the different types of failure. The main idea is that if the water delivered at each node satisfies the demand in terms of design flow and head exactly when a pipe fails, the original network is transformed into a new one with higher internal energy losses. The immediate consequence is that, in a looped network, more power must be provided at each node in order to have a sufficient surplus to be dissipated internally in case of failures; this surplus then can be used to characterize the resilience of the looped network.

Table 7.1 Measures of reliability (Source: Wagner et al. 1988b).

\begin{tabular}{|c|c|c|c|}
\hline Event-Based & Node-Related & Link-Related & System-Related \\
\hline $\begin{array}{l}\text { Type of event } \\
\text { (failure or repair) }\end{array}$ & $\begin{array}{l}\text { Total demand during the } \\
\text { simulation period }\end{array}$ & $\begin{array}{l}\text { Number of pipe } \\
\text { failures }\end{array}$ & $\begin{array}{l}\text { Total system } \\
\text { consumption }\end{array}$ \\
\hline $\begin{array}{l}\text { Interfailure time } \\
\text { and repair duration }\end{array}$ & $\begin{array}{l}\text { Shortfall (total unmet } \\
\text { demand) }\end{array}$ & $\begin{array}{l}\% \text { of time of failure } \\
\text { time for each pump }\end{array}$ & $\begin{array}{l}\text { Total number of } \\
\text { breaks }\end{array}$ \\
\hline \multirow{5}{*}{$\begin{array}{l}\text { Total events in the } \\
\text { simulation period } \\
\text { system status } \\
\text { during each } \\
\text { event(i.e., normal, } \\
\text { reduced service, or } \\
\text { failure) }\end{array}$} & Average head & $\begin{array}{l}\text { Number of pump } \\
\text { failures }\end{array}$ & $\begin{array}{l}\text { Maximum number } \\
\text { of breaks per event }\end{array}$ \\
\hline & $\begin{array}{l}\text { Number of reduced service } \\
\text { events }\end{array}$ & $\begin{array}{l}\text { Total duration of } \\
\text { failure time for each } \\
\text { pump }\end{array}$ & \\
\hline & $\begin{array}{l}\text { Duration of reduced } \\
\text { service events }\end{array}$ & & \\
\hline & Number of failure events & & \\
\hline & Duration of failure events & & \\
\hline
\end{tabular}

\subsubsection{Water Quality Concerns}

As stated previously, the research on water quality reliability has generally been very simplistic and premised on historical measurements as opposed to future potential. However, since a public water supply system may rapidly spread waterborne diseases, safe drinking water represents a crucial element to human survival, and water quality failure is the most unacceptable failure among all the three types of failures. 
Many factors may cause water quality to deteriorate between the treatment plant and the consumer. The contributing factors include: chemical and biological quality of source water (Ostfeld et al., 2002); effectiveness and efficiency of treatment process (Masago et al., 2002); adequacy of the treatment facility, storage facilities, and distribution system; age (Engelhardt et al., 2000), type, design, and maintenance of the distribution network (Goldman and Mays, 2004); and quality of treated water (Masago et al., 2002). Additionally, mechanical failure and hydraulic failure may contribute to water quality failure. For example, as time passes, the reliability of an aging system is continually decreasing. Deterioration of the water distribution system in many areas has translated into a high proportion of unaccounted-for water caused by leakage. Not only does this amount to loss of a valuable resource, it also raises concern about safe drinking water because of possible contamination arising from cracked pipes. Sadiq et al. (2004) provided a comprehensive framework to characterize the aggregate risk by identifying the risk factors and failure pathways between the treatment plant and the consumer. The water quality failure risk may be quantified by identifying each possible water deterioration pathway. For example, contamination ingress through a cracked pipe caused by pipe deterioration was identified as one pathway; its consequence is thus studied by calculating the probability of its occurrence and severity.

\section{Microbial Quality}

Microbial quality change may cause taste-and-odor problems, discoloration, slime growths, and economic problems (Clark and Grayman, 1998), and, of greatest importance, may increase the likelihood of waterborne disease. For example, pathogens break-through during treatment and ingress through cracked pipes are well-documented causes of waterborne outbreaks of cryptosporidiosis (Graun et al., 1998) and E. coli O157 respectively (Swerdlow et al., 1992). It is thus very important to understand the movement and behavior of microorganisms in a water distribution system in order to plan strategies for meeting the quality objectives in water distribution systems. An important consideration of microorganism exceedance is its regrowth in the water distribution system.

Research has concluded that microbial regrowth is highly dependent on the concentration of AOC (Assimilable Organic Carbon) and nutrients as well as temperature and $\mathrm{pH}$ of finished water (Lechevallier et al., 1996; van der Kooij, 1992; Miettinen et al., 1997; Liu et al., 2002; Ferguson and Neden 2001). Therefore, when microbial regrowth in a distribution system is studied, 
attention must be given to the quality of source water intake, seasonal temperatures, and the $\mathrm{pH}$ value of finished water.

Biofilms play a major role in the microbial characterization of drinking water quality in the distribution system. Not only do biofilms provide a variety of microenvironments for microorganism growth, they are also very important influences on quality and hydraulic consideration in drinking water distribution systems. Firstly, fouling of pipe surfaces due to biofilm formation has been associated with aesthetic problems for the consumers. Secondly, biofilm formation leads to increased head loss in a pipe system, resulting in a reduction in flow rate. Past research has concluded that macromolecules tend to accumulate at solid-liquid interfaces, creating favorable growth conditions. Despite low nutrient concentrations in water, attached bacteria may obtain sufficient nutrients from water flowing through the distribution system.

\section{Disinfectant Residual and Decay}

The presence of a disinfectant residual up to the consumer's tap is very important for control of microbial quality in drinking water distribution systems. This residual can limit the viability of microorganisms and prevent them from forming biofilms on pipe walls. Since disinfectants can react with water, pipe wall materials, or biofilms and deposits, longer residence time of a disinfectant results in decreased ability to protect water quality from microbial regrowth and other contamination events. Lund and Ormerod. (1995) provided evidence that the maintenance of free chlorine residual at $0.05 \mathrm{mg} / \mathrm{L}$ can postpone biofilm formation and sludge production in a distribution system of new plastic pipes. In practice, operational measures to improve the water quality reduce the residence time of a disinfectant by increasing the daily turnover rate of the storage tanks, consequently improving the disinfectant residual. Reducing tank volume and modifying pump programming appear to be the simplest and most efficient changes that can be performed to resolve the low chlorine concentration problem.

\section{Water Quality Reliability Study}

Most research considering water quality reliability has focused on the disinfectant residual (e.g. Gauthier et al., 2000; Mays, 2002; Constans et al., 2003; Goldman and Mays, 2004). In these studies, the water quality reliability is expressed as the probability that the residual of a specified disinfectant is between upper and lower bound concentrations. The upper and lower bound concentrations may vary with time and space (location). Some pumping schedule optimization models have the disinfectant residual reliability added 
as an additional constraint. The findings of how distribution system components, including pumping stations and storage tanks, influence the water quality also focused on disinfectant aspects, viz. the residence time. An optimized pumping schedule and storage tank size can reduce the residence time and storage daily turnover rate (Mays, 2002; Goldman and Mays, 2004). Other dimensions of optimization in the operational phase are to optimize the disinfectant booster location, the booster schedule, and booster dose (Boccelli et al., 1998).

Mays (2002) considered water quality reliability from the disinfectant residual perspective. His model evaluated water quality reliability in terms of chlorine residual, considering the water distribution system operation. The objective is to minimize the total energy cost of pumping during time period $t$. The water quality reliability is treated as two additional constraints. One is the conservation of mass of the chlorine; and the other is the concentration of the chlorine in each pipe at time $t$, which should be a value between the predefined upper and lower bounds. Since the residual chlorine concentrations are uncertain, they are chosen as independent random variables from the viewpoint of operation. The latter constraint is replaced by a probabilistic statement termed a chance constraint, expressed:

$$
P\left[L C_{n t} \leq C_{n t} \leq U C_{n t}\right] \geq \partial_{C_{t}} \quad n=1, \ldots, N ; \quad t=1, \ldots, T
$$

where:

$L C_{n t}$ and $U C_{n t}=$ lower bound and upper bound concentrations respectively,

$$
\begin{aligned}
N= & \text { total nodes in the water system } \\
T= & \text { pumps working time period, and } \\
\partial_{C_{t}}= & \text { performance probability level which can be } \\
& \text { specified and manipulated to consider the effect of } \\
& \text { uncertainty. }
\end{aligned}
$$

In an application to the City of Austin Northwest B Pressure Zone, the above methodology to optimize the pump operation schedule was adopted and resulted in a minimized pumping cost during a day (Goldman and Mays, 2004). The case study consisted of three pumps, 126 pipes of approximately 38.5 miles $(62 \mathrm{~km})$ in total length, 98 junction nodes of which 5 were pressure "watch points", and one storage tank. The system served about 31,000 residents residing in 32,000 acres (13,000 ha). 
A model to evaluate the system reliability against microbial risk was developed by Masago et al. (2002). Masago et al. conducted an annual infection risk analysis by using the field sampling data of cryptosporidium concentration. Since precipitation is considered as an important factor resulting in the increase in cryptosporidium concentration (Teunis et al. 1997), a model of cryptosporidium level increases arising from precipitation was developed and applied. The treatment removal efficiency and its failure pattern were considered. The removal efficiency was represented by a twochoice bionomial model: (a) either good removal (median 99.6\%) or (b) a degraded performance (median $70.6 \%$, the probability of occurrence $1.5 \%$ ). Consumption of unboiled water was considered as following a lognormal distribution with a median value of $0.153 \mathrm{~L} /$ day. An exponential doseresponse relationship was applied to evaluate the daily infection risk. The annual risk of infection was calculated by:

$$
R_{y}=1-\prod_{i=1}^{365}\left(1-R_{i}(x)\right)
$$

where:

$R_{y}=$ annual risk

$R_{i}=$ risk of infection on the $i t h$ day in a year,

$x=$ amount of intake cryptosporidium oocysts.

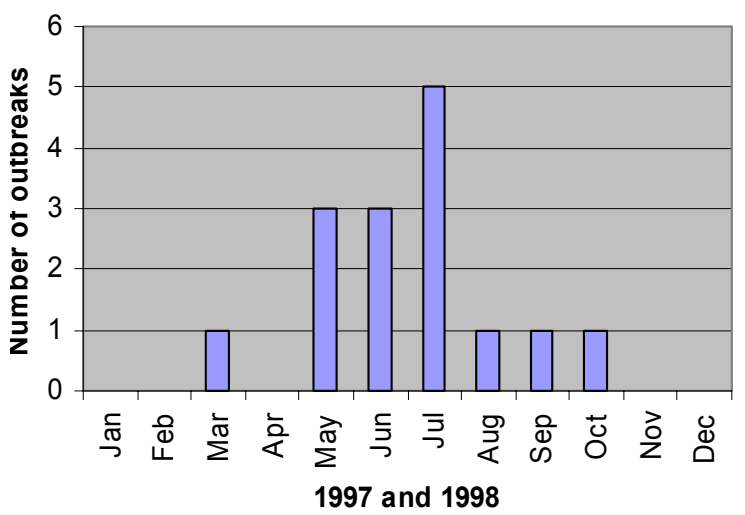

Figure 7.2 Number of waterborne-disease outbreaks associated with drinking water by microbiological agents vs. month --- US, 1997-8 $(n=17)$ (http://www.cdc.gov/mmwr/preview/mmwrhtml/ss4904a1.htm\#fig1). 


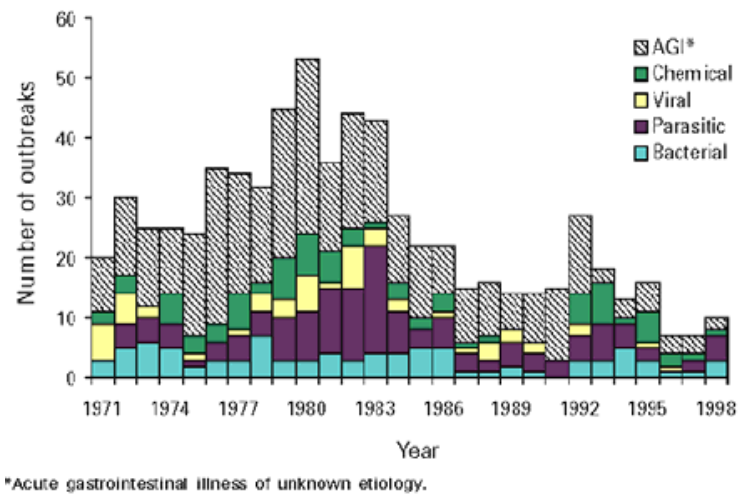

Figure 7.3 Number of waterborne-disease outbreaks associated with drinking water by year and etiologic agent ----United States, 1971-1998 $(n=691)$ (Source: Barwick et al., 2000).

Figure 7.2 shows outbreaks arising from microbiological sources, which occurred in 1997/1998 in the U.S. These outbreaks occurred primarily during the summer and fall months. Figure 7.3 illustrates the number of waterborne disease outbreaks associated with drinking water, by year. As evidenced in Figure 7.2, microbiological outbreaks are reported as the majority of waterborne disease outbreaks, and the trend over time appears to be declining numbers of outbreaks.

Table 7.2 lists documented cases of waterborne cryptosporidiosis, as reported by Butler and Mayfield (1996). It is noteworthy that most reported incidents result from deficiencies in the treatment of the raw water source; few are attributed to contaminated groundwater ingress and/or pipe breakage.

The aging problem of a water distribution system needs to be taken into account when studying the factors which cause water quality deterioration. The effect of aging infrastructure is demonstrated in the Hazen-Williams coefficients listed in Table 7.3. The implications of these values are that the carrying capacity of a twenty-year old pipe is approximately $60 \%$ of the capacity of a new pipe.

Further, Figure 7.4, which is reproduced using the data provided by Hudson (1966 and 1973) and Clarke et al. (1981), indicates the reduction over time in carrying capacity of distribution systems. With increasing densities of population, and increasing in water demand per capita, e.g. in Austin, Texas, the water consumption per capita has increased by $6 \%$ per year (Mays and 
Tung, 1992), the likelihood of low water pressure in water distribution systems will definitely be exacerbated.

Table 7.2: Waterborne outbreaks of cryptosporidiosis (Abstracted from http://www.inweh.unu.edu/inweh/cryptosporidium/1x6_s6.htm\#6.2)

\begin{tabular}{|c|c|c|c|}
\hline Location & \# Infected & Source Water & Suspected Cause \\
\hline $\begin{array}{l}\text { Cobham, Surrey, UK } \\
1983 \& 1985\end{array}$ & $\begin{array}{l}16(1983), 50 \\
(1985)\end{array}$ & spring & NA \\
\hline Braun Stn, Tex, 1984 & 2006 & ground water & Sewage contaminant well \\
\hline Sheffield UK, 1986 & 84 & surface & Cattle feces in storm run-off \\
\hline $\begin{array}{l}\text { Carrollton Georgia } \\
1987\end{array}$ & 12,960 & surface & Treatment deficiencies \\
\hline Ayrshire UK 1988 & $27+$ & NA & $\begin{array}{l}\text { Pipe cross-connect'n, cattle } \\
\text { feces }\end{array}$ \\
\hline $\begin{array}{l}\text { Swindon/ Oxford- } \\
\text { shire, UK } 1989\end{array}$ & 516 & surface & $\begin{array}{l}\text { Filter backwash recycle, } \\
\text { cattle feces }\end{array}$ \\
\hline $\begin{array}{l}\text { Loch Lomond, UK } \\
1990\end{array}$ & 147 & surface & NA \\
\hline $\begin{array}{l}\text { Isle of Thanet UK } \\
1990-91\end{array}$ & 47 & surface & Treatment deficiencies \\
\hline Pennsylvania 1991 & 551 & ground water & Treatment deficiencies \\
\hline Jackson Oregon 1992 & 15,000 & spring/ surface & Treatment deficiencies \\
\hline Milwaukee Wisc, 1993 & 403,000 & surface & Treatment deficiencies \\
\hline
\end{tabular}

Table 7.3 Change of Friction Coefficients over time for Cast-Iron Pipe (Source: Steel, 1960; and Mays and Tung, 1992).

\begin{tabular}{cc}
\hline Age & Value of ' $\mathrm{C}$ ' \\
\hline New & 130 \\
5 years & 120 \\
10 years & $107-113$ \\
20 years & $90-100$ \\
30 years & $75-90$ \\
\hline
\end{tabular}


Trend Curves For Head Loss Tests

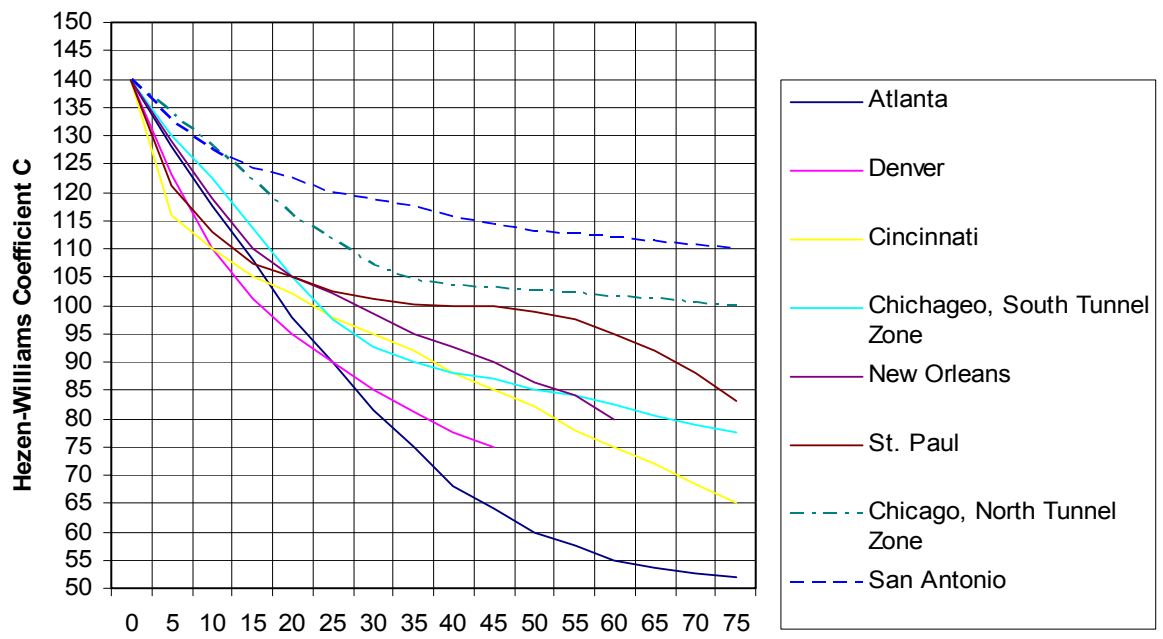

Figure 7.4 Trend curves for head loss tests.

To quantify the water quality reliability, the first concern is the definition of a meaningful and computationally feasible reliability measure. For example, Mays (2000) defined the water quality reliability as the probability that the concentrations of contaminants do not exceed the maximum contaminant level (MCL), or that residual disinfectant level is above a certain level. Concerns include:

a. Development of a failure reliability index. How to integrate the probability with the consequence of a water quality failure. For example, considering two cases, one case with the concentration of 1.5 times of the MCL, and another case with the concentration of 2.0 times of the MCL, how to distinguish between the two cases by using a single reliability measure; and

b. Accounting for multiple constituents. If more than one contaminant is studied, how to integrate the different failure probabilities into a single meaningful reliability measure. To reach a rational solution, a comprehensive risk rating system may need to be established and applied in the water quality reliability study. 


\subsection{Conclusions and Future Research}

This chapter has reviewed the development of reliability studies on water distribution systems. To date, most research of network reliability has focused on mechanical failure and hydraulic failure. While a number of reliability models have been developed to conduct mechanical and/or hydraulic reliability analysis (e.g. Goulter and Coals, 1986; Su et al., 1987, Wagner et al., 1988a and 1988b; Hobbs and Beim, 1988; Mays, 1996; Xu et al., 1998; Ostfeld 2001; Engelhardt et al., 2000; Todini, 2000; Hosoi and Kido, 2001; Shinstine et al., 2002; Kalungi and Tanyimboh, 2003), the literature on water quality failures, and reliability has been significantly less. As a public water supply system is one of the easiest ways for the spread of waterborne diseases, safe drinking water is a crucial element to human survival, and more information is needed. Waterborne pathogens and chemical contaminants may result in significant morbidity and mortality.

To quantify the water quality reliability, water quality modeling tools need to be incorporated. Scenario-based simulation approaches will play a significant role in water quality reliability studies. Additionally, mechanical failures and hydraulic failures may be causative factors for water quality failures. Past research on mechanical failures and hydraulic failures provide a good basis for water quality reliability assessment. Comprehensive water quality reliability measures and protocols need to be defined and established.

\section{References}

Babovic, Vladan; Drecourt, Jean-Philippe; Keijzer, Maarten; Hansen, Peter Friss; (2002). "A data mining approach to modeling of water supply assets", Urban Water, 4 (2002), pp. 401-414

Barwick, Rachel S; Levy, Deborah A.; Craun, Gunther F.; Beach, Michael J. ; Calderon, Rebecca L. (2000). "Surveillance for waterborne-disease outbreaks---United States, 1997-1998", http://www.cdc.gov/mmwr/preview/mmwrhtml/ss4904a1.htm

Ben-Akiva, Moshe and Gopinath, Dinesh; (1995). "Modeling Infrastructure Performance and User Costs", Journal of Infrastructure System, 1(1), pp33-43

Boccelli, Dominic L.; Tryby, Michael E.; Uber, James G.; Rossman, Lewis A.; Zierolf, Michael L.; and Marios M. Polycarpou; (1998). "Optimal Scheduling of Booster Disinfection in Water Distribution Systems”, J. Water Resour. Plng. and Mgmt. v.124, p. 99

Butler, Barbara J. and Mayfield, Colin I. (1996). "Cryptosporidium spp. - A Review of the Organism, the Disease, and Implications for Managing Water Resources", http://www.inweh.unu.edu/inweh/cryptosporidium/1x6_s.htm 
Clark, R. M.; Grayman, Walter M. (1998). "Modeling Water Quality in Drinking Water Distribution Systems" Publisher: Denver, CO: American Water Works Association, ISBN: 0898679729

Clarke, D., McBean,E., and Al-Nassri, S.; (1981) "Uncertainties in Water Distribution Systems", ASCE Journal of Hydraulics Division, Vol. 107, No. HY10, October, pp. 263-267.

Constans, Sophie; Bre'mond, Bernard; and Morel, Paul; (2003). "Simulation and Control of Chlorine Levels in Water Distribution Networks "; Journal of Water Resources Planning and Management. v. 129, n. 2, p. 135, 11 p

Craun, Gunther F.; Hubbs, Stephen A.; Frost, Floyd; Calderon, Rebecca L.; and Via, Steve H. (1998). "Waterborne outbreaks of cryptosporidiosis", Journal AWWA, Volume 90, issue 9, pp. 81-91

Cullinane, M.; Lansey, K. and Mays, L.; (1992). "Optimization-availability based design of water-distribution networks", Journal of Hydraulic. Engineering, ASCE 118(3), ppp420-441

Engelhardt, M. O., Skipworth, P. J., Savic, D. A., Saul, A. J., \& Walters, G. A. (2000). "Rehabilitation strategies for water distribution networks: a literature review with a UK perspective", Urban Water, 2(2), 153-170.

Ferguson, A. Mark D. and Neden, Douglas G. (2001). “Greater Vancouver's drinking water treatment program", Can. J. Civ. Eng. v28,n1, p 36-48

Fujiwara, O., Tung, H. D.; (1991). "Reliability improvement for water distribution networks through increasing pipe size", Water Resour. Res. Vol. 27 , No. 7 , p. 13951402

Fujiwara, O.; Li, J. ; (1998). "Reliability analysis of water distribution networks in consideration of equity, redistribution, and pressure-dependent demand", Water Resour. Res. Vol. 34 , No. 7 , pp. 1843-1850

Gale, P.; (2001). “A Review: Developments in microbiological risk assessment for drinking water”, Journal of Applied Microbiology, 2001, 91(2), 191-205

Graun, G. F.; Hubbs, S. A., F; Frost, F.; Calderon, R. L. and Via, S. H. (1998). "Waterborne outbreaks of cryptosporidiosis", Journal of American Water Works Association, 90(9), 81-91

Gauthier, Vincent; Besner, Marie-Claude; Barbeau, Benoit; Millette, Robert; and Michèle Prévost; (2000). "Storage Tank Management to Improve Drinking Water Quality: Case Study", J. Water Resour. Plng. and Mgmt. v. 126, p. 221,

Goldman, Fred E. and Mays, Larry W.; (2004). "The Application of Simulated Annealing to the Optimal Operation of Water System". http://www.public.asu.edu/ lwmays/research_paper.htm

Goulter, Ian C; (1988). "Measures of Internal Redundancy in Water Distribution Network Layouts", Journal of Information and Optimization Science, 9:363-390

Goulter, Ian C; and Coals, A.; (1986). "Quantitative approaches to reliability assessment in pipe networks", J. Hydraul. Eng., 116(2), 211-229

Goulter, Ian C and Kazemi, A. (1988). "Spatial and temporal groupings of water main pipe breakage in Winnipeg", Canadian Journal of Civil Engineering, 15(1), 91-97

Hobbs, B. F.; and Beim, G. K. ; (1988). "Analytical simulation of water system capacity reliability”, Water Resources Research, 24(9). 1431-1444 
Hosoi, Y; and Kido, Y; (2001). "Water Supply Systems-Comparative Reliability Analysis of The Distribution Areas of A Water Supply System and Its Application for An Earthquake Risk Analysis”, Water Science and Technology-Water Supply, v.1,n.4 p. $217,10 \mathrm{p}$

Hudson, W., (1966). "Studies of Distribution System Capacity in Seven Cities", Journal of the American Water Works Association, Vol. 58, No. 2, February 1966.

Hudson, W., (1973). "Computerizing Pipeline Design:, ASCE - Transportation Engineering Journal, Vol. 99, No. TE1, February 1973.

Jacobs, P., and Goulter, Ian C.; (1988). "Evaluation of Methods for Decomposition of Water Distribution Networks for Reliability Analysis”, Civil Engineering Systems, 5: 58-64

Kalungi, Paul; Tanyimboh, Tiku T.; (2003). "Redundancy model for water distribution systems", Reliability Engineering and System Safety, 82(2003), pp. 275-286

Kleiner, Yehuda; and Rajani, Balvant (2001). "Comprehensive review of structural deterioration of water mains: statistical model”, Urban Water, 3(2001), 131-150

Kleiner, Yehuda (2001). "Scheduling Inspection and Renewal of Large Infrastructure Assets", Journal of Infrastructure Systems, ASCE, 7(4), 136-143

LeChevallier, M. W.; Welch, N. J.; and Smith, D. B.; (1996). "Full-scale studies of factors related to coliform drinking water", Applied and Environmental Microbiology. v. 62, n. 7, p. 2201, 11 p.

Liu, W.; Wu, H.; Wang, Z.; Hong; S.L.; Hu; J. Y.; Ng, W.J. (2002).'Investigation of assimilable organic carbon (AOC) and bacterial regrowth in drinking water distribution system", Water Research, 36 (2002) 891-898

Lund, Vidar and Ormerod, Kari; (1995). "The influence of disinfection processes on biofilm formation in water distribution systems", Water Research, v. 29, n.4, pp. 10131021

Masago, Y.; Katayama, H.; Hashimoto, A.; Hirata, H.; and Ohagaki, S.; (2002). "Assessment of risk of infection due to Cryptosporidium parvum in drinking water", Water Science and Technology, v 46, n. 11-12, pp. 319-324

Mays, Larry W; Tung, Y. K. (1992). "Hydrosystem Engineering and Management (McGraw-Hill Series in Water Resources and Environmental Engineering)", McGrawHill, NY, ASIN: 0070411468

Mays, Larry W; (1996). "Review of reliability analysis of water distribution system", Stochastic Hydraulics, Proceedings of the Seventh IAHR International Symposium

Mays, Larry W; (2000). Chapter 18: Reliability Analysis for Design, AWWA, "Water Distribution Systems Handbook” Edited by Mays, Larry W., Publisher: New York; London: McGraw-Hill, c2000, ISBN:0071342133.

Mays, Larry W.; Lansey, Kevin and Tung, Y. K.; (2002). Chapter 10: Reliability and Availability Analysis of Water Distribution, Urban Water Supply Handbook, Edited by Mays, Larry W., Publisher: New York: McGraw-Hill, c2002, ISBN: 0071371605

Micevski, Tom; Kuczera, George and Coombes, Peter (2002). "Markov Model for Storm Water Pipe Deterioration", Journal of Infrastructure Systems, ASCE, Volume 8, Issue 2, pp. $49-56$

Miettinen, I.; Vartiainen, T.; and Martikainen, P. J.; (1997). "Microbial Growth and Assimilable Organic Carbon in Finnish Drinking Waters". Wat. Sci. Tech., Vol. 35, No. 11-12, pp. 301-306 
Ostfeld, Avi ; (2001). "Reliability analysis of regional water distribution systems", Urban Water, 3(2001), pp. 253-260

Ostfeld, Avi ; Kogan, Dimitri; Shamir, Uri; (2002). "Reliability simulation of water distribution systems - single and multiquality”, Urban Water, 4(2002), pp. 53-61

Prasad, T. Devi and Park Nam-Sik; (2004). "Multiobjective Genetic Algorithms for Design of Water Distribution Networks", Journal of Water Resources Planning and Management, Vol. 130, No. 1, January 1, 2004

Rajani, Balvant and Kleiner, Yehuda; (2001). "Comprehensive review of structural deterioration of water mains: physically based models”, Urban Water, 3(2001), 177190

Sadiq, Rehan; Kleiner, Yehuda and Rajani, Balvant; (2004). "Aggregative Risk Analysis for Water Quality Failure in Distribution Networks", Journal of Water Supply: Research and Technology - AQUA, 53(4), pp: 241-260

Sakarya, A. Burcu Altan and Mays, Larry W.; (2000). "Optimal Operation of Water Distribution Pumps Considering Water Quality”, J. Water Resour. Plng. and Mgmt. v. 126, p. 210

Selçuk, A. Sevtap; and Yücemen, M. Semih; (2000). "Reliability of Lifeline Networks with Multiple Sources under Seismic Hazard",Natural Hazards 21: pp:1-18

Shamir, U. and Howard, C. D. D. (1979). "An analytic approach to scheduling pipe replacement", Journal of the American Water Works Association, 71(5), 248-258

Shinstine, Debbie S.; Ahmed, Iffekhar; and Lansey, Kevin E.; (2002). "Reliability/ Availability Analysis of Municipal Water Distribution Networks: Case Study", Journal of Water Resources Planning and Management. v. 128 , n. 2 , p. 140,12 p

Steel, E. W., (1960). "Water Supply and Sewerage", McGraw-Hill, NY, ASIN: 6001008027

Su, Y.; Mays, L.; Duan, N.; and Lansey,K.; (1987). "Reliability Based Optimization for Water Distribution Systems", ASCE Journal of Hydraulic Engineering, 113:589-596

Swerdlow, D.L., Woodruff, B.A., Brady, R.C., Griffin, P.M., Tippen, S., Donnell, D., Geldreich, E., Payne, B.J., Meyer, A., Wells, J., Greene, K.D., Bright, M., Bean, N.H., Blake, P.A.; (1992). "A waterborne outbreak in Missouri of Escherichia coli O157:H7 associated with bloody diarrhea and death", Annals of Internal Medicine 117, 812-819.

Tanyimboh, T. T.; Burd, R.; Burrows, R.; Tabesh, M.; (1999), "Modelling and reliability analysis of water distribution systems", Water Science and Technology Volume: 39, Issue: 4, pp. 249-255

Teunis, P.F.M.; Medema, G.J.; Kruidenier, L.; Havelaar, A.H.; (1997). "Assessment of the risk of infection of Cryptosporidium or Giardia in drinking water from a surface water source" Water Res 1997 pp. 1333-1346

Todini, Ezio; (2000). "Looped water distribution networks design using a resilience index based heuristic approach", Urban water, 2(2000), pp. 115-122

Tolson, Bryan; Maier, Holger R.; Simpson, Angus R.; and Lence, Barbara J.; (2004). "Genetic Algorithms for Reliability-Based Optimization of Water Distribution Systems”, J. of Water Resources Planning and Management. v. 130, n. 1, pp. 63-72

van der Kooij, D. (1992). "Assimilable organic carbon as an indicator of bacterial regrowth", Journal of the American Water Works Association, 84, 57-66 
Wagner, J., U. Shamir, and D. Marks, (1988a). "Water Distribution Reliability: Analytical Methods", ASCE Journal of Water Resources Planning and Management, 114:253275 ,

Wagner, J., U. Shamir, and D. Marks, (1988b). "Water Distribution Reliability Simulation Methods", ASCE Journal of Water Resources Planning and Management, 114:276293,

Walski, T. M.; (1982). "Economic Analysis for Rehabilitation of Water Mains", Journal of Water Resources Planning and Management Division ASCE, 108 (WR3), pp:296-307

$\mathrm{Xu}$, Chengchao and Goulter, Ian C; (1998). "Probabilistic Model for Water Distribution Reliability", Journal of Water Resources Planning and Management. v. 124 , n. 4 , p. 218-230 